Journal of Business Management and
Economic Research
2019, 3 (11) DOI: $10.29226 /$ TR1001.2019.169
Journal Homepage: $\underline{\text { https://www.jobmer.org }}$

\title{
CHALLENGES FACING THE PERFORMANCE OF CATHOLIC HEALTHCARE FACILITIES IN TANZANIA: INSIGHTS FROM TURIANI AND MIKUMI HOSPITALS IN MOROGORO
}

\author{
Fr. Francis Kunambi Kolongo \\ Jordan University College
}

\begin{abstract}
A critical challenge in today's dynamic and turbulent organizations is to retain capable, competent, and skilled workforce. This reality has an enormous impact on healthcare institutions which undergo a catalogue of challenges in health service delivery. The ultimate objective of this study was to assess challenges facing the performance of Catholic healthcare facilities in Tanzania in three dimensions; human resources, leadership and managing of financial resources.

A mixed method approach and case study research design were undertaken to assess the challenges facing the performance of Catholic healthcare facilities in Tanzania. Turiani and Mikumi Hospitals in Morogoro Region were taken as the empirical study areas of the research. A total of 121 participants out of 123 (98\%) were involved in the study. Self-administered structured questionnaires, interview, observation and document analysis were used as tools for collecting quantitative and qualitative data. Descriptive and inferential statistics were employed through the use of IBM SPSS Statistics v.20. The research instruments had an excellent internal consistency with Cronbach's alpha of 0.962 . The factor analysis was suitable and appropriate with KMO test of 0.865 and Bartlett's test for Sphericity of $(\mathrm{P}<0.001)$. The findings reveal that, Catholic healthcare is experiencing challenges arising from deficiency in managing human resource. These challenges include weak leadership; inadequacy in managing financial resource, divided loyalty, lack of engagement, and a decline in both commitment and enthusiasm for work. These challenges have stalled health care delivery and have gradually weakened performance in health services delivery. In order to improve this, the leadership, management team and governing board of the hospitals should work closely with employees of Turiani and Mikumi hospitals to re-align themselves with the hospitals' vision, mission and goals to rescue the future of Catholic healthcare. The Tanzania Catholic Church Health Policy of June, 2008 is hereby highly recommended as a yardstick for continuous improvement.
\end{abstract}

Key words: Financial resources, challenges, hospitals, Morogoro 


\subsection{Background of the Problem}

For centuries, the Catholic Church has been a major social actor in provision of healthcare services. A convergence of powerful forces at the beginning of the twenty first century severely threatened the future of Catholic healthcare (White, 2013). Catholic healthcare facilities are obliged to carry out traditional values of serving the poor and respecting the sanctity of life, while also remaining modern, efficient, and compliant with regulatory bodies. Above all, Catholic healthcare providers simultaneously face powerful pressures toward organizational conformity in an increasingly secular world (Cochran \& White, 2002). Experience in Tanzania reveals that these challenges are not uncommon (Pheng \& Rui, 2016).

Observation and experience reveals that, previously when Catholic healthcare facilities were under missionary founders, the performance of Catholic healthcare facilities in Tanzania was unmatched and because of their great attitude of empathy and concern for people, loyalty and respect for leaders, unshakable healthcare ethics, an affinity for virtue, humility and ability to admit mistakes (Berlucchi, 2011). At this point in time, the Church unwaveringly offered its basic health services on a charitable basis and not to accumulate financial gain.

According to Berlucchi (2011), current experience shows that Catholic healthcare is under-performing and failing to achieve basic healthcare milestones. This has been in one way or another instigated by putting less emphasis on personal and professional development and fundamental healthcare goals. Catholic healthcare is highly dependent on a number of organs and makes insignificant efforts to be initiative. At the same time, there is inadequate management of personnel who provide healthcare services, a fact which lowers the quality of services provided and demotivates enthusiastic healthcare personnel.(Ibid).

Most studies suggest that, a conducive working environment and living conditions, management and supervision, career advancement and training, keeping staff healthy, and improving salaries and benefits are significant to secure employees and augment performance (Aklilu, 2012). Conversely, loyalty, commitment, engagement, and enthusiasm of the workforce as well as the quality and performance of Catholic healthcare is gradually deteriorating, causing high employee attrition and demoralization. Likewise, "Opinion surveys continue to reveal that health employee loyalty, commitment and engagement are decreasing" (Dye, 2010). The purpose of this study was therefore to assess and determine challenges facing the performance of Catholic healthcare facilities in the three dimensions of human resource, leadership, and financial resource. The study also proposes relevant and practical solutions to counteract the above-mentioned challenges. 


\subsection{Literature Review}

\subsection{Empirical Literature Review}

Most of the existing literature on Catholic healthcare are based only on anecdotal and theological discussions of how Catholic healthcare may be different. Only few studies have managed to compare nonCatholic facilities with those that are Catholic, mainly in provision of services. The comparison is rooted in specific elements like stewardship of resources, access to vulnerable populations, compassionate care and outpatient services (White et al., 2010). According to Kutney-Lee et al., (2014) “How Catholic healthcare compete in a growing market-oriented hospital environment remains a significant challenge, and one in which there is little empirical data to provide evidence of outcomes." A study by Thomson Reuters conducted in 255 hospital systems in United States involving four ownership categories (Catholic, other churches, investor-owned, not-for-profit) found that, Catholic operated hospitals had significant and better indicators of quality performance than investor owned institutions. Other church-owned, non-Catholic, and not-for-profit facilities lagged behind Catholic hospitals as well (Foster, 2010). The findings of the Reuters study suggest that Catholic Hospital leaders have been successful in aligning the management of Catholic hospitals with their specific mission of serving compressive healthcare to vulnerable populations. However, the Reuters study provides very limited data from which administrators can base their decisions (Foster, 2010).

A research conducted by Kutney-Lee et al (2014) at the University of Pennsylvania, Philadelphia titled “Distinct enough? A National Examination of Catholic Hospital Affiliation and Patient Perceptions of Care" aimed to test the following hypothesis: "Higher percentages of patients treated in Catholic hospitals will report more favorable experiences with their care-as measured by the HCAHPS survey-compared with patients treated in non-Catholic hospitals." "Findings revealed that patients treated in Catholic hospitals appear to rate their hospital experience similar to patients treated in non-Catholic hospitals. Catholic hospitals maintain a very slight advantage above their non-Catholic peers on five HCAHPS (Hospital Consumer Assessment of Healthcare Providers and Systems) measures related to nurse communication, receipt of discharge information, quietness of the room at night, overall rating, and recommendation of the hospital; yet, these differences were minimal".

Another study was guided by the Donabedian (1988) framework for assessing the quality of health care and the extant literature on Catholic hospital outcomes in the United States as well as patient satisfaction. 
The Donabedian model suggests a linear relationship between three key elements: Structure (capitalintensive aspects of a health system, including Catholic affiliation), Process (the administration of care itself) and Outcomes (discrete changes in a patient's health status, including patient satisfaction). Prior research has shown that several structural aspects of a hospital are associated with patient satisfaction ratings (Kutney-Lee, et al., 2009). The Donabedian model suggests that these relationships are a result of differences in process or the actual delivery of healthcare. Catholic healthcare literature cites multiple reasons why patients might be more satisfied when they are admitted for a hospital stay, including the delivery of spiritually based and compassionate healthcare (Keehan, 2012; Timm, 2012).

\subsection{Research Gap}

The theoretical and empirical review conducted shows that, although a great deal is known about healthcare organizational characteristics, less is known about how Catholic healthcare organizations differ empirically from other organizational ownership forms. (White, 2000, Kutney-Lee et al, 2014). In Tanzania, Catholic healthcare plays a critical role in the provision of healthcare yet the empirical evidence in these institutions is practically very minimal in literatures. Literature review conducted shows that little attempt has been made to unveil the challenges facing the performance of Catholic healthcare facilities in Africa, particularly in Tanzania whereby one third of healthcare services is covered by the Catholic Church. Therefore, this has necessitated a need to carry out research in order to assess the challenges facing the performance of Catholic healthcare facilities in Tanzania specifically in Turiani and Mikumi hospitals.

\subsection{Research Methodology}

A mixed method approach and case study research design were undertaken to assess the challenges facing the performance of Catholic healthcare facilities in Tanzania. The study zeroed down on Turiani and Mikumi Hospitals in Morogoro Region as case study. A total of 121 participants out of 123 (98\%) were involved in the study. Self-administered structured questionnaires, interview, observation and document analysis were used as tools for collecting quantitative and qualitative data. Descriptive and inferential statistics were employed through the use of IBM SPSS Statistics v.20. The research instruments had an excellent internal consistency with Cronbach's alpha of 0.962. The factor analysis was suitable and appropriate with KMO test of 0.865 and Bartlett's test for Sphericity of $(\mathrm{P}<0.001)$. 


\subsection{Results}

\subsection{Demographic Characteristics}

The general characteristics of respondents in the study area were as follows:

Table 4.1: Respondents Demographic Characteristics

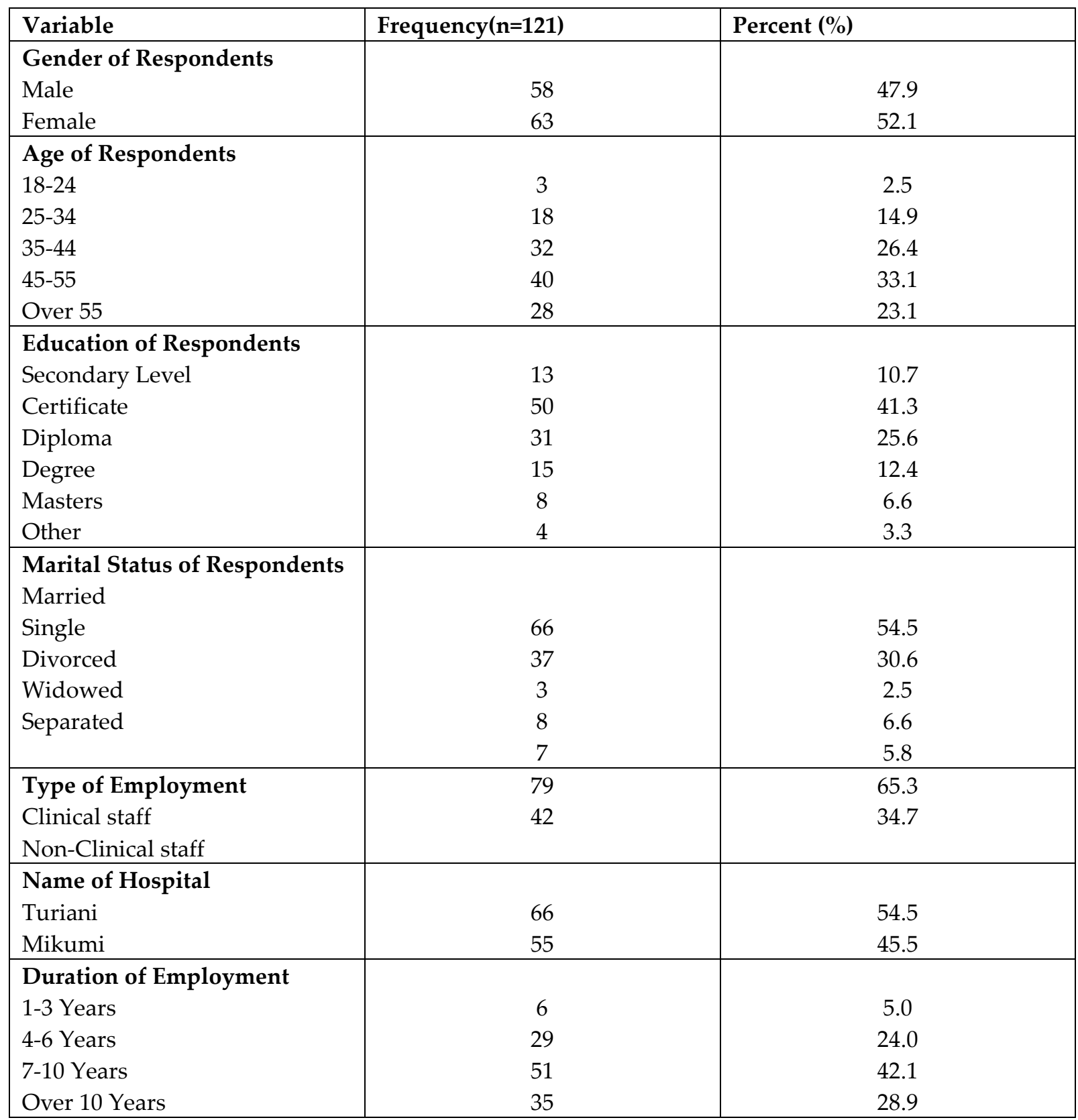

\section{Field data (2019)}

There were more females (52.1\%) than males who covered $47.9 \%$ of the respondents as depicted by Table 1 . Majority of the respondents were between $45-55$ years covering $33.1 \%$ of the respondents while $26.4 \%$ of the respondents were between $35-44$ years. $14.9 \%$ of the respondents were between $25-35$ years while $23.1 \%$ 
of the respondents were 55 years and above. Most of the respondents were married (54.5\%) while the rest of the respondents $(30.6 \%)$ were single. The number of clinical staff surpassed the number of non-clinical staff by $65.3 \%$ which implies that majority of the respondents were professional health workers (Table 4.1 )

\subsection{Main Findings of the Study}

In this section, the analysis and findings of the study is presented based on the results extracted from the IBM SPSS v20 and in light of literature review. The section shows how the four (4) variables and the twenty eight (28) indicators were explored. The percentage ratings of the respondents are presented in the tables and figures below.

\subsubsection{Challenges of Managing Human Resource}

This part intends to assess the challenges that Catholic healthcare facilities are confronted with when managing human resource and attempting to retain their workforce. Data in Table 4.2 presents the results of the respondents as follows:

$100 \%$ of the respondents disagreed that their hospitals had adequate staff in all key positions. Likewise, $96.7 \%$ of the respondents disagreed that hospitals recruitment and hiring policies are just and fair. Furthermore, $89.2 \%$ of respondents disagreed that hospitals support staff training and development. Equally, $99.1 \%$ of the respondents disagreed that compensation is adequate for attracting and retaining key staff. Almost $94.3 \%$ of the respondents disagreed that promotions are based primarily on performance and competence. Likewise, $95.9 \%$ of the respondents disagreed that staffs are adequate and considered competent to provide quality healthcare. On the other hand, $93.4 \%$ of the respondents disagreed that hospitals provide welfare services for employees' wellbeing. 
Table 4.2: Summative response score on human resource challenges

\begin{tabular}{|c|c|c|c|c|c|c|c|}
\hline $\begin{array}{l}\text { Human Resource items } \\
\text { Indicators }-(\%)\end{array}$ & 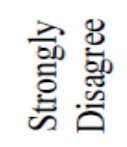 & 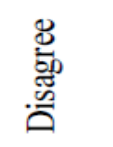 & 忢总 & 焉 & 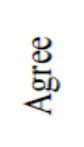 & 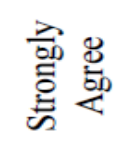 & 咅蒂 \\
\hline Adequate staff & 85.1 & 14.9 & 100 & 0 & 0 & 0 & $\mathbf{0}$ \\
\hline Recruitment & 53.7 & 43 & 96.7 & 3.3 & 0 & 0 & $\mathbf{0}$ \\
\hline Training & 53.7 & 35.5 & 89.2 & 9.1 & 1.7 & 0 & 1.7 \\
\hline Compensation & 70.2 & 28.9 & 99.1 & 0.9 & 0 & 0 & $\mathbf{0}$ \\
\hline Promotions & 57.9 & 36.4 & 94.3 & 5.7 & 0 & 0 & $\mathbf{0}$ \\
\hline Competency & 61.2 & 34.7 & 95.9 & 4.1 & 0 & 0 & $\mathbf{0}$ \\
\hline Employees wellbeing & 63.6 & 29.8 & 93.4 & 6.6 & 0 & 0 & $\mathbf{0}$ \\
\hline
\end{tabular}

These findings are also supported by interviews conducted in the course of the study. One of the key informants said:

"Inadequate staffing is a major challenge. This has left a huge burden on the available staff members who end up carrying out duties that overwhelm their capacity. As a result, there is a heavy workload leading to staff burn-out and dissatisfaction generally. Medical personnel are also under-paid and when they are paid, salaries and benefits are unduly delayed. Managing employees ultimately becomes cumbersome given these shortcomings."

In addition to the comments by the foregoing respondent, other respondents had similar sentiments. One of the respondents commented that:

"In my opinion, if you aspire to be promoted then don't work for religious organizations particularly church-owned hospitals. In such institutions, promotions are never forthcoming and minimal or no efforts are made towards employee career development. This makes it hard for employees to acquire new skills and they consequently remain challenged career-wise."

In the same tone, another respondent echoed a similar opinion by stating that:

"Recruitment and hiring policies have been overtaken by nepotism, favoritism, and cronyism. This in itself not only creates a negative perception towards the institutional leadership but also waters down the integrity and legitimacy of the leaders."

\subsubsection{Leadership Challenges}


Data in Table 4.3 presents the opinion of respondents. Practically, 100\% of the respondents disagreed that their hospitals had leaders that the organization could depend on for advancement. Likewise, $93.4 \%$ of the respondents disagreed that leaders had problem solving skills. Almost $94.2 \%$ of the respondents disagreed that there is a shared plan among members to achieve established goals. Moreover, $95 \%$ of the respondents disagreed that hospitals have clear leadership structures and decision making processes. Also, the respondents disagreed that the manner of operating governing bodies and hospital management teams was satisfactory. Percentage-wise, $98.3 \%$ and $93.4 \%$ of the respondents respectively disagreed with the mode of running governing bodies and hospital management teams. Additionally, 95.9\% of the respondents disagreed on the existence of a positive organizational climate within hospitals.

Table 4.3: Summative response score on Leadership challenges

\begin{tabular}{|c|c|c|c|c|c|c|c|}
\hline $\begin{array}{l}\text { Leadership items } \\
\text { Indicators - (\%) }\end{array}$ & $\begin{array}{l}\text { 总总 } \\
\text { 产 } \\
\text { 总 }\end{array}$ & 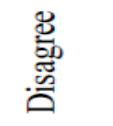 & 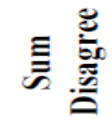 & 焉 & 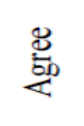 & $\begin{array}{l}\text { 해 } \\
\text { 总 } \\
\text { 总 }\end{array}$ & 恶总 \\
\hline Leaders & 76.9 & 23.1 & 100 & $\mathrm{O}$ & 0 & O & $\mathbf{0}$ \\
\hline Problem solving & 51.2 & 42.1 & 93.4 & 5.8 & 0.8 & $\mathrm{O}$ & 0.8 \\
\hline Shared plan & 52.1 & 42.1 & 94.2 & 5.0 & 0.8 & 0 & 0.8 \\
\hline Decision making & 55.4 & 39.7 & 95.0 & 0.5 & o & o & $\mathbf{0}$ \\
\hline Governance & 67.8 & 30.6 & 98.3 & 1.7 & $\mathrm{O}$ & $\mathrm{O}$ & $\mathbf{0}$ \\
\hline Management & 52.9 & 40.5 & 93.4 & 5.0 & 1.7 & 0 & 1.7 \\
\hline Organizational climate & 61.2 & 34.7 & 95.9 & 4.1 & 0 & $\mathrm{O}$ & $\mathbf{0}$ \\
\hline
\end{tabular}

Field data (2019)

These findings are in line with information acquired during interviews whereby one of the respondents' mentioned that:

"In this hospital the leaders are unsupportive and also lack mentorship skills. Most health personnel secretly wish to work in institutions with better leadership. There is always no solution to our problems because we don't have leaders who are ready and skilled to tackle these problems."

\section{Another interviewee also lamented that:}

"Decision making in this hospital is quite perturbing. Decisions take too long to be made, the management is ineffective, and there is a general lack of efficiency in carrying out various tasks. These 
challenges are eventually affecting the quality of health care delivered. It is doubtful if the governing body of this hospital understands its roles and responsibilities."

\section{Another respondent also voiced his dissatisfaction with the hospital management by stating that:}

"In this hospital the management team is weak and lacks managerial skills. This has made employees' lives not only difficult but also unbearable. The management team is continuously failing to carry out its role and lacks transparency. This in one way or another has made the hospital an unpleasant place to work in."

\subsubsection{Challenges in Managing Financial Resources}

Data in Table 4.4 highlights the responses from the respondents. $100 \%$ of the respondents disagreed that the hospitals have adequate operational funds and revenues. $89.3 \%$ of the respondents disagreed that competitive salaries are not available because of high hospital expenditures. Almost $92.6 \%$ of the respondents disagreed that hospital infrastructures are well secured and maintained. Likewise, $97.5 \%$ of the respondents disagreed that the hospitals had enough technological equipment for health services delivery. Moreover, $97.5 \%$ of the respondents disagreed that the hospitals manage to purchase medicament resources regularly.

\section{Table 4.4: Summative response score on financial resource challenges}

\begin{tabular}{|c|c|c|c|c|c|c|c|}
\hline $\begin{array}{l}\text { Financial Resources items } \\
\text { Indicators - }(\%)\end{array}$ & 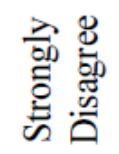 & 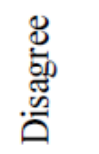 & E & $\begin{array}{l}\overline{\widetilde{U}} \\
\frac{0}{\bar{Z}}\end{array}$ & 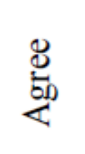 & 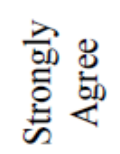 & E \\
\hline Funds & 81 & 19 & 100 & 0 & 0 & 0 & $\mathbf{0}$ \\
\hline Revenues & 64.5 & 35.5 & 100 & 0 & 0 & 0 & $\mathbf{0}$ \\
\hline Expenditures & 55.4 & 33.9 & 89.3 & 8.2 & 2.5 & 0 & 2.5 \\
\hline Infrastructures & 57 & 35.5 & 92.6 & 6.6 & 0.8 & 0 & 0.8 \\
\hline Equipment & 56.2 & 41.3 & 97.5 & 2.5 & 0 & 0 & $\mathbf{0}$ \\
\hline Medicaments & 55.4 & 42.1 & 97.5 & 2.5 & 0 & 0 & $\mathbf{0}$ \\
\hline Resources & 64.5 & 30.6 & 95 & 5 & 0 & 0 & $\mathbf{0}$ \\
\hline
\end{tabular}

Field data (2019) 
This is also supported by responses during interviews whereby an interviewee commented that:

"The challenges faced in this hospital are directly linked to inadequacy of funds to meet major recurrent and capital expenditures. Funds are usually diverted due to weaknesses in financial policies. Planning and managing the hospital budget comes with several complications since accounting procedures and financial management are mishandled. The governing body has also failed to monitor financial matters within the hospital."

\section{Another interviewee cemented the above comments by asserting that:}

"Due to financial constraints, hospital infrastructure and equipment are not adequately maintained. Nowadays due to lack of medicine at the hospital, patients are directed to buy medicine from pharmacies outside the hospital premises."

\subsection{Multiple Linear Regression Analysis}

A multiple linear regression analysis was conducted because the study involved more than one independent variable that predicts the value of the dependent variable. Henceforth, the value of Catholic healthcare Facilities (CHF) as a dependent variable was predicted by human resources (HR), leadership (L) and financial resources (FR) as independent variables. Multiple linear regressions assisted to estimate the coefficients of the linear equation of the independent variables that predicts the value of the dependent variable whereby the linear equation for multiple regressions is:

$\mathrm{Y}=\mathrm{B} 0+\mathrm{B} 1(\mathrm{HR})+\mathrm{B} 2(\mathrm{~L})+\mathrm{B} 3(\mathrm{FR})+\varepsilon$

$\mathrm{Y}=$ Catholic healthcare facilities

$\mathrm{B} 0=$ Constant

$\mathrm{B} 1=\mathrm{A}$ fractional change of human resources

B2 = A fractional change of leadership 
B3 = A fractional change of financial resources

$\varepsilon=$ Error term

Table 4.5: Model Summary Output for Multiple Regression

\begin{tabular}{|l|l|l|l|l|}
\hline Model & $\mathrm{R}$ & R Square & Adjusted R Square & $\begin{array}{l}\text { Std. Error of the } \\
\text { Estimate }\end{array}$ \\
\hline 1 & $\mathbf{. 9 1 8 a}$ & $\mathbf{. 8 4 3}$ & .839 & 1.280 \\
\hline \multicolumn{2}{|l}{ a. Predictors: (Constant), Financial Resources, Leadership, Human Resource } \\
\hline \multicolumn{2}{|l}{ b. Dependent Variable: Catholic Healthcare }
\end{tabular}

Table 4.6: Analysis of variance

\begin{tabular}{|l|l|l|l|l|l|}
\hline Model & $\begin{array}{l}\text { Sum of } \\
\text { Squares }\end{array}$ & df & Mean Square & F & Sig. \\
\hline Regression & 1028.063 & $\mathbf{3}$ & 342.688 & $\mathbf{2 0 9 . 0 2 0}$ & $.000 \mathrm{~b}$ \\
\hline Residual & 191.821 & $\mathbf{1 1 7}$ & 1.639 & 120 \\
\hline Total & 1219.884 & \multicolumn{5}{l|}{} \\
\hline \\
$\begin{array}{l}\text { a. Dependent Variable: Catholic Healthcare b. Predictors: (Constant), Financial Resources, Leadership, } \\
\text { Human Resource }\end{array}$
\end{tabular}

Table 4.7: Predictors of Challenges towards $\mathrm{CH}$

\begin{tabular}{|l|l|l|l|l|l|}
\hline \multicolumn{2}{|l|}{ Model } & \multicolumn{2}{|l|}{ Unstandardized Coefficient } & \multicolumn{2}{l|}{ Standardized Coefficients } \\
\hline $\mathrm{B}$ & Std. Error & \multicolumn{2}{|l|}{ Beta } & $\mathrm{t}$ & Sig. \\
\hline (Constant) & -256 & .432 & .421 & -592 & .555 \\
Human & .457 & .080 & .164 & 5.742 & .000 \\
Resource & .171 & .074 & .390 & 2.320 & .022 \\
Leadership & .416 & .075 & & 5.533 & .000 \\
Financial & & & & & \\
Resource & & & & & \\
\hline
\end{tabular}


The multiple linear regressions conducted show that the linear combination of human resources challenges, leadership challenges, and financial resources challenges scores was significantly related to predict Catholic healthcare facilities by $\mathrm{F}(3,117)=209.020, \mathrm{p}<0.001$ (Table 4.5). The multiple correlation coefficients was 0.918 , indicating approximately $(84.3 \%)$ of the variance of Catholic healthcare facilities can be accounted for by the linear combination of human resources, leadership and financial resources scores (Table 4.6). The regression equation for predicting the challenges of Catholic healthcare was: $\mathrm{CHF}=-256+$ $457(\mathrm{HR})+171(\mathrm{~L})+416(\mathrm{FR})+\varepsilon($ Table 4.7$)$.

\subsection{Conclusion and Recommendations}

General findings indicate that challenges facing the performance of Catholic healthcare facilities in Tanzania are significant. Major challenges lie in how to nurture and ensure sustainable delivery of high quality and safe medical care. Leadership is the most influential factor in shaping organizational climate and culture. There is clear evidence of the link between leadership and a range of important outcomes within health services, including patient satisfaction, patient mortality, organizational financial performance, staff well-being, engagement, turnover and absenteeism, and overall quality of care.

Based on the findings of the study, the key challenges facing Turiani and Mikumi hospitals are perceived by the majority of the employees from the two hospitals to be as follows: hospitals lack adequate staff in all key positions of health services delivery, recruitment and hiring policies are not just and fair, compensation is not adequate to attract and retain key staff, there are no adequate and competent staff to offer quality care, and poor provision of welfare services for employees' wellbeing. There were also insufficient leaders to push the organizations to greater heights, there were weaknesses in formal problem solving skills, there was no clear structure for decision making processes, the governing bodies do not work closely with health workers to implement hospitals' visions, missions, and goals. The management team was also generally weak and the organization slack a culture of showing appreciation to their staff. The hospitals had no adequate funds and revenues to sustain operational costs, there were weaknesses in the management of hospitals' expenditures, there were inadequate supplies and equipment to support operations for health service, and the hospitals do not buy medicament resources effectively. These challenges shape the magnitude of performance within the two hospitals. 


\subsection{References}

Aklilu, A. (2012). Healthcare Workers' Perceptions towards Hospital Leadership and Institutional Structure in Chiro and Gelemso Hospitals, West Hararghe Zone, East Ethiopia. Ethiopia: Jimma University.

Berlucchi, J. (2011). How Catholics Work Together: Ten Common Strengths and Weaknesses of Church-based Organizations. Retrieved November 9, 2018, from Catholic Education Resource Center: https://www.catholiceducation.org

Donabedian, A. (1988). The Quality of care: How can it be assessed? Journal of the American Medical Association 260(12), 1743-1748.

Dye, C. F. (2010). Leadership in Healthcare: Essential Values and Skills (2nd ed.). Chicago: Health Administration Press.

Foster, D. (2010). Differences in health system quality performance by ownership. Retrieved December 05, 2017, from Thomson Reuters: Study_Finds_Quality_in_Nonprofit_Health_Systems_Betterwith_Church-Owned_the_Best.pdf

Keehan, C. (2012). Our greatest treasures. Health Progress 93(1), 4-5.

Pheng, L. S., \& Rui, Z. (2016). Service quality for Facilities Management in Hospitals. Singapore: Springer.

White, K. (2000). Hospitals Sponsored by the Roman Catholic Church: Separate, Equal, and Distinct? The Milbank Quarterly, Vol. 78, No.2, 213-239.

White, K., Chou, T., \& Dandi, R. (2010). Catholic hospital services for vulnerable populations: are system values sufficient determinants? Health Care Management Review 35(2), 175-186.

Kutney-Lee, A., Melendez-Torres, G., McHugh, M., \& Wall, B. M. (2014). Distinct enough? A national examination of Catholic hospital affiliation and patient perceptions of care. Health Care Manage Rev. 39(2), 134-144.

Timm, K. (2012). An examination of conscience: The Catholic identity of Catholic health care. Health Progress 93(1), 7-11. 